\title{
Differences in hypertension between informal and formal areas of Ouagadougou, a sub-Saharan African city
}

Boukaré Doulougou ${ }^{1,2^{*}}$, Séni Kouanda ${ }^{2}$, Clémentine Rossier ${ }^{3,4}$, Abdramane Soura $^{3}$ and Maria Victoria Zunzunegui ${ }^{1,5,6}$

\begin{abstract}
Background: Countries of sub-Saharan Africa are increasingly confronted with hypertension and urbanization is considered to favor its emergence. This study aims to assess the difference in the prevalence of hypertension between formal and informal urban areas of Ouagadougou and to determine the risk factors associated with hypertension in these urban populations of sub-Saharan Africa.
\end{abstract}

Methods: A cross-sectional survey was conducted in 2010 on 2041 adults aged 18 years and older in formal and informal areas of Ouagadougou. Data was collected through personal interviews conducted at home. Blood pressure and anthropometric measurements were taken by trained interviewers. Logistic regressions were fitted to identify factors associated with hypertension.

Results: The overall prevalence of hypertension was 18.6\% (95\% confidence interval [CI], 16.9-20.3) and its detection was $27.4 \%(95 \% \mathrm{Cl}, 22.9-31.9)$. Prevalence of hypertension in formal settings was $21.4 \%$ (95\% Cl, 19.0-23.8), significantly higher than prevalence in informal settings: $15.3 \%$ (95\% Cl, 13.0-17.6). However, this difference disappeared after adjusting for age. In addition to age, being an unmarried woman (odds ratio $[\mathrm{OR}]=1.7 ; 95 \%$ $\mathrm{Cl}, 1.1-2.4)$, recent rural-to-urban migration $(\mathrm{OR}=1.8 ; 95 \% \mathrm{Cl}, 1.2-2.8)$, obesity $(\mathrm{OR}=1.8 ; 95 \% \mathrm{Cl}, 1.1-3.1)$ and physical inactivity $(\mathrm{OR}=1.9 ; 95 \% \mathrm{Cl}, 1.2-3.0)$, were independent risk factors for hypertension.

Conclusions: Hypertension is common among the adult population of Ouagadougou but its detection is low. While there are no differences between formal and informal areas of the city, rural-to-urban migration emerges as an independent risk factor. Known risk factors as obesity and physical inactivity are confirmed while the vulnerability of unmarried women and rural-to-urban migrants maybe specific to this west African population.

Keywords: Hypertension, Prevalence, Risk factors, Adult population, Rural-to-urban migrants, Ouagadougou

\section{Background}

Developing countries are undergoing the epidemiological transition with the emergence of non-communicable diseases $[1,2]$. Among the factors contributing to this transition are the increase in life expectancy at birth, rapid unplanned urbanization with poor health habits (increased sedentary lifestyle, increased smoking and alcohol consumption) and the nutrition transition [3-5]. Of an estimated 36 million

\footnotetext{
* Correspondence: boukare.doulougou@umontreal.ca

'Département de Médecine Sociale et Préventive, École de santé publique, Université de Montréal, 850 Rue Saint Denis, 3ème étage, Bureau S03-806,

Montréal, QC H2X 0A9, Canada

${ }^{2}$ Institut de Recherche en Sciences de la Santé (IRSS), 03 BP 7192

Ouagadougou, Burkina Faso

Full list of author information is available at the end of the article
}

deaths from non-communicable diseases in the world in $2008,48 \%$ were caused by cardiovascular disease, $80 \%$ took place in developing countries [5]. Hypertension is identified as the main risk factor for cardiovascular disease [6]. In African countries, the prevalence of hypertension in adult populations varies between $20-34 \%$ and seems to be increasing [7-9]. This prevalence is higher in urban than in rural areas $[7,10,11]$. Urbanization has been proposed as the main factor driving these differences and the increasing trends $[5,11]$.

In the cities of developing countries, formal areas characterized by adequate spatial planning and utilities (water, electricity, telephone, road infrastructure) and informal areas with no urban development could be frequently 
distinguished [12]. According to United Nations estimates, due to the accelerated urbanization, the absolute numbers of people living in slums in the low and middle-income countries rose from 760 million in 2000 to 863 million in 2012. Sub-Saharan Africa was the region with the largest proportion (62\%) of urban population living in slums [12]. In spite of their importance, very little is known about hypertension prevalence in these informal areas.

In 2003, a cross-sectional study found hypertension prevalence of $23 \%$ among population aged 18 and over in Ouagadougou, but it did not report separately for informal and formal areas of the city and did not examine risk factors [13]. A recent study among population aged 35 years and over from Ouagadougou, reported a prevalence of $40 \%$ with differences in hypertension prevalence between formal and informal areas (comparative morbidity figure $=$ 1.15; 95\% CI, 0.99-1.34) [14]. But this study did not examine traditional risk factors as smoking, alcohol intake or chronic conditions neither differences between populations of rural and urban extraction. Our study therefore aims to assess the difference in the prevalence of hypertension between formal and informal urban areas of Ouagadougou and to identify the risk factors associated with hypertension in these urban populations of subSaharan Africa.

\section{Methods}

\section{Study site}

Burkina Faso is a developing country located in West Africa with its capital Ouagadougou. In 2006, the population of Ouagadougou was 1.5 million and is expected to reach 5.8 million by 2030 [15]. Since 2008, the Institut Supérieur des Sciences de la Population (ISSP) of the Universite de Ouagadougou established a population observatory called Ouagadougou Health and Demographic Surveillance System in Burkina Faso (Ouaga HDSS) (www.issp.bf/opo/). In 2010, the Ouaga HDSS covered five neighborhoods ( 2 formal and 3 informal) at the northern periphery of Ouagadougou with around 80000 residents living in 18 310 households [15]. Ouaga HDSS is affiliated to the International Network for the Demographic Evaluation of Populations and Their Health (INDEPTH), which included 49 observatories in 20 countries of Africa, Oceania and Asia (www.indepth-network.org).

\section{Data}

Data come from the health survey carried out between February and August 2010 in Ouaga HDSS site. A sample of 1941 households were randomly selected and in each household every subject 15 years and older was invited to participate. A response rate of $87.5 \%$ was recorded at the household level. For this article, only adults 18 years and older will be included to facilitate comparison with previous research on hypertension prevalence.
Questions were administered face to face by trained interviewers using pocket PCs. The adult questionnaire included 8 sections (description of health, accidents and violence, depression, lifestyle (physical activity, smoking, alcohol consumption, nutrition), access to health services, chronic diseases, anthropometric measurements and measurement of blood pressure). Information on age, education, marital status, migration status, occupation of participants were informed by routine collection of the surveillance system. The questions were administrated in French and Moore (the main local language).

Out of the 2210 participants aged 18 years and older drawn for the survey, 169 participants $(7.65 \%)$ were excluded from the present analysis because they were out of home during the survey. The final sample size for this work was 2041.

\section{Variables}

Outcome: Blood pressure (BP) was measured on a single occasion at the house of the participant by the trained interviewer using a digital automatic sphygmomanometer (Omron 3) with an appropriate cuff size. Three BP measures were done at the beginning of the interview after at least 5 minutes' rest, and three other BP measures were taken at the end of interview in seating position. BP was taken successively at least 30 seconds apart on the same arm. For analysis, we use the mean of the last two measurements [16]. Individuals with a systolic $\mathrm{BP} \geq 140 \mathrm{~mm}$ $\mathrm{Hg}$ and/or diastolic $\mathrm{BP} \geq 90 \mathrm{~mm} \mathrm{Hg}$, were considered to be hypertensive. Detection of hypertension was defined as self-reporting of any prior diagnosis of hypertension by a healthcare professional among those who had blood pressure readings suggesting hypertension.

\section{Independent variables}

Age, sex, marital status, place of residence, read/write capability and occupational status were inquired. Formal areas have cadastral organization with streets and public services such as electricity, tap water, telephone, school, sanitation. Informal areas are squatter settlements and have no cadastral organization or public services. Migration status was described by two variables: the duration of residence in Ouagadougou coded into 3 categories (native of Ouagadougou, migrants who reside for less than 10 years, migrants who reside for 10 years and over); the provenance of participant coded into 3 categories (Ouagadougou for those who were born there; those coming from outside of Ouagadougou; foreign for those coming from other countries). Chronic conditions were assessed by asking the participant whether he/she had ever been told by a health professional that he/she had chronic disease such as diabetes mellitus, chronic bronchitis or asthma, stroke, arthritis, gout, stomach ulcer, cancer, AIDS, heart problems, tuberculosis and epilepsy. Participants were classified as 
chronically ill (those who have at least one of the listed diseases) and non-chronically ill, otherwise.

Smoking status was assessed by indicating whether the participant smoked tobacco products at the time of the survey. Participant alcohol intake was assessed with items from WHO's Alcohol Use Disorders Identification Test (AUDIT) [17]. The frequency of alcohol consumption during the last 12 months was asked and the responses were "never", "once a month or less", "two to four time per month", " two to three times per week", "four to six time per week", and "daily". For the analysis, participants were classified in three groups: Never for "never" answer; Occasionally for the 3 answers "once a month or less", "two to four time per month" and " two to three times per week"; Frequently for the 2 answers "four to six time per week", and "daily".

Physical activity was assessed by asking participants how many days in the last week they practice physical activity (strenuous physical, labor, bicycling, walking) for at least 10 minutes. Participants were classified as: low for those who had carried out physical activity one day or those accounting for less than 2 hours/week; intense for those who carried out physical activity for at least 4 days/week and for more than seven hours; moderate for the remaining group.

Participant's weight was measured to the nearest $0.01 \mathrm{~kg}$ using a digital scale. Height was assessed to the nearest $0.01 \mathrm{~m}$ using a wooden stadiometer. Body mass index (BMI) was calculated by dividing the weight $(\mathrm{kg})$ by the square of the height $\left(\mathrm{m}^{2}\right)$. The participant was classified as underweight when $\mathrm{BMI}<18.5$; normal weight when $18.5 \leq$ $\mathrm{BMI}<25$; overweight when $25 \leq \mathrm{BMI}<30$; obese when $\mathrm{BMI} \geq 30$.

\section{Statistical analysis}

The prevalence of hypertension was estimated according to each risk factor. Differences in prevalence of hypertension by levels of categorical risk factors were assessed by using Chi square tests. T-test was used for the comparison of means. In order to estimate adjusted odds ratios for each hypertension risk factor logistic regressions were fitted. All statistical tests were two-tailed and a $P$-value $\leq$ 0.05 was considered statistically significant. Given the known vulnerability of widows and separated women, sex stratified analyses of civil status by hypertension was conducted and a combined variable "sex by civil status" included in the logistic model taking as reference the group of married women. Lastly, to account for possible dependence of some observations taken in the same household (1973 individuals in 1940 households), generalized estimating equations were fitted producing results very similar to those of fitted logistic regressions without accounting for clustering. All statistical analyses were performed using IBM SPSS 20 for Windows.

\section{Ethics}

The protocol of the health survey was approved by the Ethics Committee for Health Research of the Ministry of Health of Burkina Faso. Informed consent was obtained from all participants.

\section{Results}

Of the 2041 subjects included in this analysis, $45.8 \%$ lived in informal settings, 23\% were native of Ouagadougou, $64 \%$ came from outside of Ouagadougou of whom $90 \%$ came from rural areas. Table 1 shows the sex specific characteristics of participants. Both men and women, subjects in the informal setting were younger, tended to live more frequently in marriage and were less able to read and write compared to the formal setting. Informal area has more migrants under 10 years than formal area. Considering each sex, the presence of chronic conditions was not different between formal and informal areas, while overweight, obesity were more frequent in formal than in informal settings. Subjects of informal areas were more often smokers compared with formal settings $(11.7 \%$ vs $6.8 \% ; P<0.001)$. Among men, those in formal settings consumed more alcohol and had less physical activity than those from informal settings.

The prevalence of hypertension in the overall sample was $18.6 \%$ [95\% confidence interval [CI], 16.9-20.3]. The formal setting had a prevalence of hypertension of $21.4 \%$ [95\% CI, 19.0-23.8], while the prevalence in informal settings was $15.3 \%$ [95\% CI, 13.0-17.6] and the difference was statistically significant. The weighted prevalence of hypertension was 10.4\% [95\% CI, 8.7-12.1] in informal areas and $16.7 \%$ [95\% CI, 14.8-18.7] in formal areas. In both areas, not being able to read and write, coming from place outside of Ouagadougou and increasing age were associated with increased prevalence of hypertension (Table 2). The largest difference in the prevalence of hypertension between the areas occurred in middle age (Figure 1). In both informal and formal setting, the presence of self-reported chronic disease was not associated with hypertension and physical activity was associated with a decrease in prevalence. BMI and alcohol consumption were associated with hypertension, only in formal settings. Smoking was negatively associated with hypertension in informal settings but not in formal settings (Table 2).

Given the lack of significant difference in hypertension prevalence between the formal and informal areas we fitted a multivariate logistic model to the whole sample to assess the significance of independent risk factors in both areas. As expected there was a significant gradient of higher hypertension prevalence with increasing age. Unmarried women were more likely to be hypertensive than married women and no differences were observed between married women and men, after adjustment for all remaining covariates in the model. Recent migrants to 
Table 1 Characteristics of the participants by sex and by residence, Ouagadougou

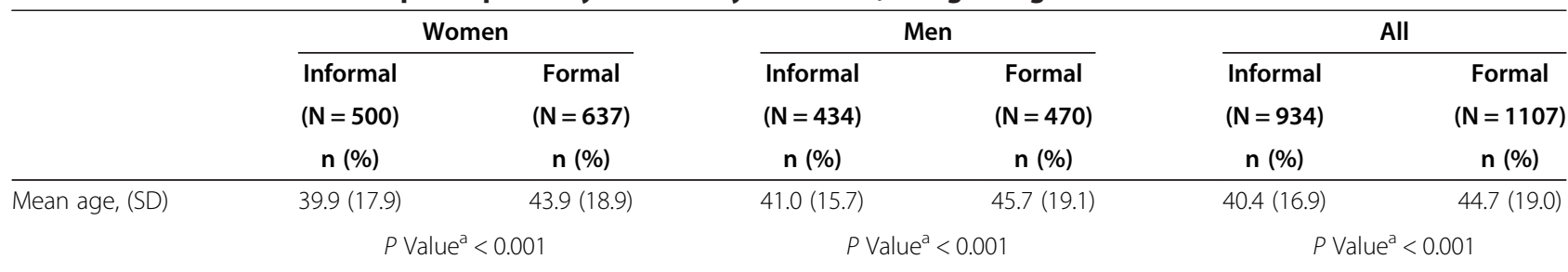

Civil status

\begin{tabular}{lcc} 
Married & $352(70.4)$ & $368(57.8)$ \\
Other & $148(29.6)$ & $269(42.2)$ \\
& \multicolumn{2}{c}{$P$ Value < 0.001} \\
Read/Write & $400(80.0)$ & $423(66.4)$ \\
No & $100(20.0)$ & $214(33.6)$ \\
Yes & \multicolumn{2}{c}{$P$ Value $<0.001$} \\
& $23(4.8)$ & $36(6.0)$ \\
Occupational status & \\
Employed & $188(39.6)$ & $205(34.3)$ \\
Independent & $264(55.6)$ & $356(59.6)$ \\
Unpaid job & \multicolumn{2}{c}{$P$ Value $=0.18$}
\end{tabular}

\section{Duration of residence in Ouagadougou}

\begin{tabular}{llr} 
Native & $91(18.7)$ & $170(28.0)$ \\
$<10$ years & $203(41.8)$ & $122(20.1)$ \\
$\geq 10$ years & $192(39.5)$ & $315(51.9)$ \\
& \multicolumn{2}{c}{$P$ Value $<0.001$}
\end{tabular}

\section{Chronic conditions}

No

Yes

$$
\begin{array}{lr}
408(81.6) & 521(81.8) \\
92(18.4) & 116(18.2) \\
2 & \text { P Value }=0.93
\end{array}
$$

\section{Body Mass Index}

\begin{tabular}{lcc}
$<18.5$ & $58(11.6)$ & $60(9.4)$ \\
18.5 to 24.99 & $329(65.8)$ & $354(55.6)$ \\
25.0 to 29.9 & $89(17.8)$ & $154(24.2)$ \\
$\geq 30$ & $24(4.8)$ & $69(10.8)$ \\
& \multicolumn{2}{c}{$P$ Value $<0.001$}
\end{tabular}

\section{Smoking status}

No

Current smoker

$$
\begin{array}{cc}
493(98.6) \quad & 635(99.7) \\
7(1.4) \quad 2(0.3) \\
\multicolumn{2}{c}{P \text { V Value }=0.05}
\end{array}
$$

\section{Alcohol intake}

\begin{tabular}{lcc} 
Never & $370(74.0)$ & $450(70.6)$ \\
Occasionally & $93(18.6)$ & $145(22.8)$ \\
Frequently & $37(7.4)$ & $42(6.6)$ \\
& \multicolumn{2}{c}{$P$ Value $=0.22$}
\end{tabular}

$$
\begin{array}{cr}
348(80.2) & 311(66.2) \\
86(19.8) & 159(33.8) \\
\multicolumn{2}{c}{P \text { Value }<0.001}
\end{array}
$$

$$
\begin{array}{lr}
700(74.9) & 679(61.3) \\
234(25.1) & 428(38.7) \\
\multicolumn{2}{c}{P \text { Value }<0.001}
\end{array}
$$

$$
\begin{array}{cr}
290(66.8) & 238(50.6) \\
144(33.2) & 232(49.4) \\
\multicolumn{2}{c}{P \text { Value }<0.001}
\end{array}
$$

$690(73.9)$

$661(59.7)$

$244(26.1)$

$P$ Value $<0.001$

$$
\begin{array}{cc}
91(21.6) & 108(24.4) \\
207(49.0) & 153(34.6) \\
124(29.4) & 181(41.0) \\
\multicolumn{2}{c}{P \text { Value }<0.001}
\end{array}
$$

$$
\begin{array}{cc}
96(22.5) & 122(26.9) \\
145(34.0) & 59(13.0) \\
186(43.6) & 272(60.0)
\end{array}
$$

$P$ Value $<0.001$

$$
\begin{array}{lr}
114(12.7) & 144(13.9) \\
395(44.0) & 358(34.5) \\
388(43.3) & 537(51.6) \\
\multicolumn{2}{c}{P \text { Value }<0.001}
\end{array}
$$

$$
\begin{array}{lr}
187(20.5) & 292(27.5) \\
348(38.1) & 181(17.1) \\
378(41.4) & 587(55.4) \\
\multicolumn{2}{c}{P \text { Value }<0.001}
\end{array}
$$

$$
\begin{array}{lrlr}
366(84.3) & 395(84.0) & 774(82.9) & 916(82.7) \\
68(15.7) & 75(16.0) & 160(17.1) & 191(17.3) \\
\multicolumn{2}{c}{P \text { Value }=0.90} & \multicolumn{2}{c}{P \text { Value }=0.94}
\end{array}
$$

$$
\begin{array}{cc}
44(10.1) & 56(11.9) \\
339(78.1) & 322(68.5) \\
48(11.1) & 73(15.5) \\
3(0.7) & 19(4.0) \\
\multicolumn{2}{c}{P \text { Value }=0.001}
\end{array}
$$$$
102(10.9)
$$$$
116(10.5)
$$

$$
27 \text { (2.9) }
$$$$
88(7.9)
$$

$P$ Value $<0.001$
$332(76.5) \quad 397(84.5)$
$102(23.5)$
$73(15.5)$
$P$ Value $=0.002$
$825(88.3) \quad 1032(93.2)$
109 (11.7) $\quad 75(6.8)$
$P$ Value $<0.001$
$281(64.7)$
$263(56.0)$
$106(24.4) \quad 160(34.0)$
$47(10.8)$
$47(10.0)$
$P$ Value $=0.006$

$651(69.7)$

$713(64.4)$

$84(9.0)$

89 (8.0)

$$
P \text { Value }=0.005
$$


Table 1 Characteristics of the participants by sex and by residence, Ouagadougou (Continued)

\begin{tabular}{|c|c|c|c|c|c|c|}
\hline \multicolumn{7}{|c|}{ Physical activity } \\
\hline Low & $291(58.2)$ & $402(63.1)$ & $173(39.9)$ & $256(54.5)$ & $464(49.7)$ & $658(59.4)$ \\
\hline Moderate & $159(31.8)$ & $188(29.5)$ & $166(38.2)$ & $135(28.7)$ & 325 (34.8) & $323(29.2)$ \\
\hline \multirow[t]{2}{*}{ Intense } & $50(10.0)$ & $47(7.4)$ & 95 (21.9) & 79 (16.8) & $145(15.5)$ & $126(11.4)$ \\
\hline & \multicolumn{2}{|c|}{$P$ Value $=0.15$} & \multicolumn{2}{|c|}{$P$ Value $<0.001$} & \multicolumn{2}{|c|}{$P$ Value $<0.001$} \\
\hline
\end{tabular}

Abbreviation: SD, standard deviation.

abtained by T-test; other $P$ Value were obtained by $X^{2}$ test.

${ }^{b}$ Variable with missing values (65 among women and 40 among men).

Pvalues for comparisons of participants from informal areas to those from formal areas.

Ouagadougou (those arriving in the last 10 years) were more likely to be hypertensive than those born in Ouagadougou while the odds of being hypertensive did not differ between the more established migrants (more than 10 years) and the native population. As expected, obese people and those with low physical activity were more likely to be hypertensive while those who drank occasionally had lower odds of hypertension than those who never drank (Table 3).

Among participants with elevated blood pressure readings suggestive of hypertension, the prevalence of detection was $27.4 \%$ (95\% CI, 22.9-31.9). The proportion of these hypertensive participants aware of their condition was higher in formal setting than in informal setting (31.2\% versus $21.0 \%$; $P=0.03$ ), but no difference was observed according to sex.

\section{Discussion}

Our study shows that in the city of Ouagadougou, hypertension is common. There is no significant different in prevalence between informal and formal areas after age adjustment. Area specific analyses showed that factors such as older age, illiteracy, coming from an area of Burkina outside of Ouagadougou, physical inactivity are found as risk factors for hypertension in both formal and informal areas. In formal areas, those undernourished or with frequent alcohol consumption are more likely to be hypertensive. Among women, being unmarried was associated with hypertension.

The overall prevalence found in this study (18.6\%) is somewhat lower than prevalence of previous studies conducted in the same population: For the same age group (18 years and over), a previous study reported 23\% [13]. Considering participant aged 35 years and over, our results show a prevalence of $30.1 \%$ ( $95 \% \mathrm{CI}, 27.5-32.8$ ) less than $40 \%$ found in 2007 [14]. This does not mean that hypertension in Ouagadougou is declining. A reason for this conflictive results could be that in the current study no information on hypertensive medication was available. Despite our lower estimate, this study confirms that hypertension prevalence remains higher in the urban areas than in semi-urban and rural areas in Burkina [11]. However, the hypertension prevalence in the current study was lower that prevalence found in other African urban population aged 16 and over that showed prevalence between 30 to $41 \%$ [8,18-20].

The lack of significant difference in age adjusted hypertension prevalence between the informal areas compared to formal areas of this study corroborates the results of Niakara among people aged 35 years and over [14], which found no significant age-adjusted difference between these two types of urban areas of Ouagadougou.

Associations of hypertension with older age, high BMI and physical inactivity corroborate previous results $[14,18,21]$. Both high BMI and physical inactivity are consequences of urbanization.

Migration from sub-Saharan African countries to western countries was identified as a risk factor of hypertension [22]. Our study shows that rural-to-urban within-country migration is positively associated with hypertension. Comparing the results of this study to our previous study in rural and semi-urban areas in the region of Kaya (Burkina Faso) and for the same age group, the prevalence of hypertension among migrants in Ouagadougou is higher than in rural areas [11]. Explanatory factors for this positive association could be the same as those found in international migration: anxiety and stress first, then changes in diet and physical inactivity [23]. Unwin also showed that after 12 months of migration from rural to urban areas, physical activity was significantly lowered and fat intake was increased among migrants in Tanzania [24] and that after the first twelve months of migration, blood pressure among migrants fell in both men and women [24]. This drop in blood pressure could be followed later by its elevation consequence of the poor health behaviors which are gradually acquired. Our finding that migrants under 10 years have higher odds of hypertension even after extensive covariates is contrary to those found in Dakar in Senegal, where a lower prevalence of hypertension was found in recent migrants [25]. This difference may be due to the origin of the migrants which were almost rural in our study while in Dakar, they mostly come from other cities in Senegal [25]. So the urbanization contrast between the areas they are coming from and the host areas could explain this difference.

After adjustment, there was no significant difference between migrants over 10 years (63\% of those who have 
Table 2 Prevalence of hypertension by residence in adult population of Ouagadougou

\begin{tabular}{|c|c|c|c|c|}
\hline & \multicolumn{2}{|r|}{ Informal } & \multicolumn{2}{|r|}{ Formal } \\
\hline & $\mathrm{N}$ & $\%(95 \% \mathrm{Cl})$ & $\mathrm{N}$ & $\%(95 \% \mathrm{Cl})$ \\
\hline All (unweighted) & 934 & $15.3(13.0-17.6)$ & 1107 & $21.4(19.0-23.8)$ \\
\hline All (weighted) & 1277 & $10.4(8.7-12.1)$ & 1386 & 16.7 (14.8-18.7) \\
\hline \multicolumn{5}{|l|}{ Sex } \\
\hline Female & 500 & 16.4 (13.1-19.7) & 637 & $20.4(17.3-23.6)$ \\
\hline \multirow[t]{2}{*}{ Male } & 434 & $14.1(10.8-17.3)$ & 470 & $22.8(19.0-26.6)$ \\
\hline & \multicolumn{2}{|r|}{$P$ Value $=0.32$} & \multicolumn{2}{|c|}{$P$ Value $=0.35$} \\
\hline \multicolumn{5}{|l|}{ Age, y } \\
\hline $18-24$ & 168 & $2.4(0.05-4.7)$ & 220 & $2.7(0.6-4.9)$ \\
\hline $25-34$ & 289 & $3.8(1.6-6.0)$ & 209 & $5.3(2.2-8.3)$ \\
\hline $35-44$ & 133 & $12.8(7.0-18.5)$ & 118 & $14.4(8.0-20.8)$ \\
\hline $45-54$ & 123 & 19.5 (12.4-26.6) & 175 & $27.4(20.8-34.1)$ \\
\hline $55-64$ & 114 & $33.3(24.6-42.1)$ & 203 & $36.0(29.3-42.6)$ \\
\hline \multirow[t]{2}{*}{$65+$} & 107 & $45.8(36.2-55.4)$ & 182 & $45.1(37.8-52.3)$ \\
\hline & \multicolumn{2}{|c|}{$P$ Value $<0.001$} & \multicolumn{2}{|c|}{$P$ Value $<0.001$} \\
\hline
\end{tabular}

Civil status

Married

Other

Read/Write

No

Yes

$$
\begin{array}{cccc}
700 & 12.7(10.2-15.2) & 679 & 22.4(19.2-25.5) \\
234 & 23.1(17.6-28.5) & 428 & 19.9(16.1-23.7) \\
P \text { Value }<0.001 & & P \text { Value }=0.32
\end{array}
$$

$$
\begin{array}{cccc}
690 & 18.0(15.1-20.8) & 661 & 27.2(23.8-30.6) \\
244 & 7.8(4.4-11.2) & 446 & 12.8(9.7-15.9) \\
P \text { Value }<0.001 & \multicolumn{2}{c}{P \text { Value }<0.001}
\end{array}
$$

\section{Occupational status $^{\mathrm{a}}$}

$\begin{array}{lcccc}\text { Employed } & 114 & 7.9(2.9-12.9) & 144 & 17.4(11.1-23.6) \\ \text { Independent } & 395 & 15.2(11.6-18.7) & 358 & 24.9(20.4-29.4) \\ \text { Unpaid job } & 388 & 16.8(13.0-20.5) & 537 & 21.2(17.8-24.7) \\ & & P \text { Value }=0.07 & & P \text { Value }=0.16\end{array}$

Duration of residence in Ouagadougou ${ }^{\mathrm{a}}$

$\begin{array}{lcccc}\text { Native } & 187 & 10.7(6.2-15.2) & 292 & 11.3(7.7-15.0) \\ <10 \text { years } & 348 & 14.4(10.7-18.1) & 181 & 17.1(11.6-22.7) \\ \geq 10 \text { years } & 378 & 18.0(14.1-21.9) & 587 & 27.9(24.3-31.6) \\ & & P \text { Value }=0.07 & & P \text { Value }<0.001\end{array}$

Provenance

\begin{tabular}{lcccc} 
Ouagadougou & 187 & $10.7(6.2-15.2)$ & 292 & $11.3(7.7-15.0)$ \\
Outside of Ouagadougou & 658 & $17.3(14.4-20.2)$ & 649 & $27.4(24.0-30.9)$ \\
Foreign & 68 & $5.9(0.1-11.6)$ & 119 & $14.3(7.9-20.7)$ \\
& \multicolumn{3}{c}{$P$ Value $=0.007$} & \multicolumn{3}{c}{$P$ Value $<0.001$}
\end{tabular}

\section{Chronic conditions}

No

$$
\begin{array}{cccc}
774 & 15.9(13.3-18.5) & 916 & 20.7(18.1-23.4) \\
160 & 12.5(7.3-17.7) & 191 & 24.6(18.4-30.8) \\
P \text { Value }=0.28 & \multicolumn{2}{c}{P \text { Value }=0.24}
\end{array}
$$

Table 2 Prevalence of hypertension by residence in adult population of Ouagadougou (Continued)

\section{Body Mass Index}

$<18.5$

18.5 to 24.99

25.0 to 29.9

$\geq 30$

$$
\begin{array}{cccc}
102 & 19.6(11.7-27.4) & 116 & 31.9(23.3-40.5) \\
668 & 14.8(12.1-17.5) & 676 & 17.8(14.9-20.6) \\
137 & 14.6(8.6-20.6) & 227 & 23.8(18.2-29.4) \\
27 & 14.8(0.5-29.1) & 88 & 29.5(19.8-39.3) \\
c & P \text { Value }=0.65 & \multicolumn{2}{c}{P \text { Value }=0.001}
\end{array}
$$

\section{Smoking status}

No

$$
\begin{array}{cccc}
825 & 16.4(13.8-18.9) & 1032 & 21.8(19.3-24.3) \\
109 & 7.3(2.4-12.3) & 75 & 16.0(7.5-24.5) \\
P \text { Value }=0.01 & P \text { Value }=0.24
\end{array}
$$

Current smoker

Alcohol intake

Never

$$
\begin{array}{cccc}
651 & 15.5(12.7-18.3) & 713 & 22.3(19.2-25.4) \\
199 & 11.6(7.1-16.0) & 305 & 15.1(11.0-19.1) \\
84 & 22.6(13.5-31.8) & 89 & 36.0(25.8-46.1) \\
\multicolumn{2}{c}{P \text { Value }=0.06} & \multicolumn{2}{c}{P \text { Value }<0.001}
\end{array}
$$

Occasionally

Frequently

Physical activity

\begin{tabular}{lcccc} 
Low & 464 & $19.6(16.0-23.2)$ & 658 & $24.5(21.2-27.8)$ \\
Moderate & 325 & $10.8(7.4-14.2)$ & 323 & $19.5(15.2-23.9)$ \\
Intense & 145 & $11.7(6.4-17.0)$ & 126 & $10.3(4.9-15.7)$ \\
& & $P$ Value $=0.001$ & & $P$ Value $=0.001$ \\
\hline
\end{tabular}

Abbreviation: $\mathrm{Cl}$, confident interval.

${ }^{a}$ Sample sizes do not add to total because information was not available for all participants for these variables.

migrated more than 10 years ago had been in Ouagadougou more than 20 years) and natives reflecting the fact that after a long time of exposure to the city of Ouagadougou, hypertension patterns in immigrants converge with those of the natives, probably due to similar exposures to the city, similar health behavior and stress, similar opportunities of diagnosis and treatment and similar survival patterns. Also it is likely that rural-to-urban immigrants over 10 years arrived at a time when the city

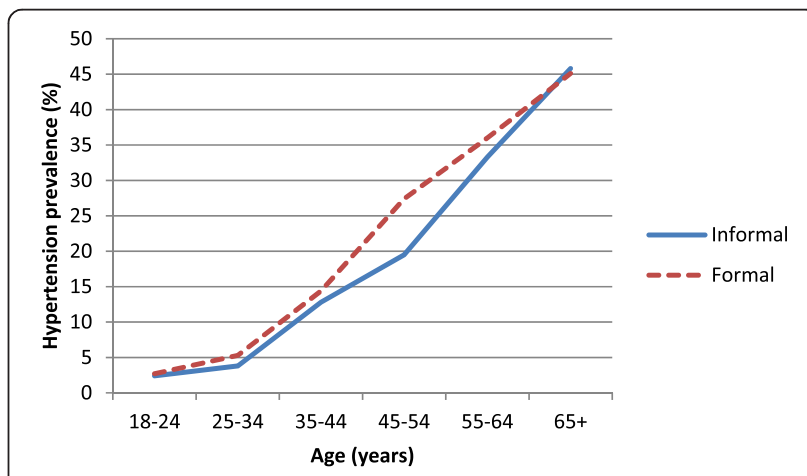

Figure 1 Hypertension distribution by age and residence areas in Ouagadougou adult population. 
Table 3 Hypertension associated factors and corresponding multivariate odds ratios in Ouagadougou adult population $^{\mathrm{a}}$

\begin{tabular}{|c|c|c|c|c|c|}
\hline \multirow[t]{2}{*}{ Characteristics } & \multirow[t]{2}{*}{ N (\% HT) } & \multicolumn{2}{|c|}{ Unadjusted } & \multicolumn{2}{|c|}{ Adjusted } \\
\hline & & OR $(95 \% \mathrm{Cl})$ & $P$ value & OR $(95 \% \mathrm{Cl})$ & $P$ value \\
\hline \multicolumn{6}{|l|}{ Age, y } \\
\hline $18-24$ & $368(2.7)$ & 1 & & 1 & \\
\hline $25-34$ & $485(4.1)$ & $1.5(0.7-3.3)$ & 0.27 & $1.7(0.8-3.7)$ & 0.21 \\
\hline $35-44$ & 245 (13.9) & $5.8(2.8-11.9)$ & $<0.001$ & $6.2(2.9-13.3)$ & $<0.001$ \\
\hline $45-54$ & $291(24.4)$ & $11.6(5.8-22.9)$ & $<0.001$ & $11.1(5.3-23.1)$ & $<0.001$ \\
\hline $55-64$ & $310(35.5)$ & $19.7(10.1-38.5)$ & $<0.001$ & $18.5(9.0-38.1)$ & $<0.001$ \\
\hline $65+$ & $274(44.2)$ & $28.3(14.5-55.4)$ & $<0.001$ & $22.8(10.9-47.6)$ & $<0.001$ \\
\hline
\end{tabular}

Civil status by sex

Married women

Unmarried women

Married men

Unmarried men

\section{Read/Write}

Yes

No

Residence

Informal

Formal

\section{Duration of residence in Ouagadougou}

Native

$<10$ years

$\geq 10$ years

479 (11.1)

$529(15.3)$

$965(24.0)$

Body Mass Index

$\begin{array}{lc}<18.5 & 211(26.1) \\ 18.5 \text { to } 24.99 & 1300(16.2) \\ 25.0 \text { to } 29.9 & 353(20.4) \\ \geq 30 & 109(25.7)\end{array}$

\section{Smoking status}

No

Current smoker

$1793(19.4)$

Alcohol intake
Never

Occasionally

Frequently

Physical activity

Intense

Moderate

$259(11.2)$

$623(15.1)$

1091 (22.3)

$1316(19.0)$

$490(13.7)$

$167(29.3)$

Low

Abbreviation: $\mathrm{OR}$, odds ratio; $\mathrm{Cl}$, confident interval; $\mathrm{HT}$, arterial hypertension.

adjusted model was fit on the complete data set ( $\mathrm{N}=1973$ participants) and took the clustering at household level into account.

$P$ Values were obtained by Wald tests.

$0.7(0.5-0.9) \quad 0.008$

$1.8(1.2-2.5)$

0.002

1

$1.4(0.9-2.2)$

0.13

$<0.001$

$\begin{array}{ccc}<0.001 & 1.7(1.1-2.4) & 0.007 \\ <0.001 & 1.3(0.9-1.8) & 0.13 \\ 0.01 & 1.1(0.6-2.1) & 0.85\end{array}$

$<0.001$

$1.1(0.8-1.5)$

0.66

1

$1.5(1.2-1.9)$

$<0.001$

$1.2(0.9-1.6)$

0.16

1

$1.5(1.0-2.1)$

0.05

1.8 (1.2-2.8)

0.006

$2.5(1.8-3.5)$

$<0.001$

$1.4(0.9-1.9)$

$1.8(1.3-2.6)$

0.001

$1.0(0.7-1.5)$

0.90

1.3 (1.0-1.8)

0.07

1

$1.8(1.1-2.9)$

0.01

$1.4(1.0-2.0)$

0.05

0.02

1

$0.5(0.3-0.8)$

0.004

$1.2(0.7-2.0)$

0.61

1

$0.7(0.5-1.0)$

0.05

1.1 (0.7-1.6)

0.69

$1.3(0.8-2.1)$

0.29

$1.9(1.2-3.0)$

0.005 
was smaller with consequent less stressful transitions from rural to urban contexts.

Unmarried people have higher prevalence of hypertension. This is consistent with our previous results in the semi-urban of Kaya, in the north central of Burkina Faso [11] but the current study has further identified that the higher prevalence of hypertension in unmarried people is restricted to unmarried women, meaning divorced (4\%) and widowed (61\%). Being widow is rare among African men, for whom re-marriage and polygamy are the social norm. Thus, our findings lead us to suggest that women who are widows are particularly vulnerable for hypertension in Burkina Faso compared to married women of similar age, education and health behaviors. Authors have also previously shown the high vulnerability of widows [26].

Moderate alcohol consumption was associated with a lower prevalence of hypertension even after extensive adjusting. This protective effect of light-to-moderate alcohol consumption has been shown by previous research in developed countries [27]. Even more, contrary to other studies, frequent alcohol consumption (4 times and over/week) was not significantly associated with hypertension but misclassification bias could hinder detection of an elevated odds ratio in the highest category of alcohol consumption. Different methods to quantify alcohol consumption make direct comparisons with previous studies difficult. However Pires et al. found a borderline association between hypertension and frequent alcohol consumption ( more than 3 days/week) in men with an odds ratio $[\mathrm{OR}]$ of $1.4(95 \% \mathrm{CI}, 0.9-2.2, P=0.08)$ [28]. Future studies to better describe the problem in the African context are desirable.

Smoking appears to be a protective factor for hypertension in the informal environment; this negative association of smoking with hypertension was found in previous studies in Ghana ( $\mathrm{OR}=0.3$; 95\% CI, 0.1-0.7) [10]. However, this finding is confounded by age since smoking was more frequent in the younger population and, as expected, this association disappears in the age adjusted analysis as in other studies conducted in Africa [29,30].

Our study shows that about one quarter of hypertensive adults knew their condition and that corroborates with previous results $(30 \%)$ on the same population of Ouagadougou [31]. This proportion is low compared to that reported in Ghana (34.0\%) [18]. Also, treatment of hypertension among adult population of Ouagadougou remains low (less than half hypertensive adults) according to that previous study [31]. Mass prevention by acting on risk factors should be a priority in order to shift the distribution of risk factors to lower levels of risk [32]. In addition, detection of hypertensive people in the community and clinical management of hypertension should improve. The modifiable risk factors identified in this study (BMI, physical activity) are aspects that need to focus, without forgetting other aspect as lifestyle and dietary habits [33]. Special surveillance of risk groups such as rural-to-urban migrants and widows are also very important in prevention. This prevention could be translated into actions through awareness and screening campaigns for hypertension, already suggested by other authors in the African context [34].

The main limitation of this study was the lack of data on medication. This lack of information hinder our ability to identify hypertensive people under control of BP. This would entail an underestimation of prevalence. Estimates on the proportion of hypertensive people achieving controlled BP varies (between 3 and 16\%) in African studies $[7,20]$. Thus, the true prevalence in our sample would be underestimated by less than $10 \%$ of the true value.

\section{Conclusions}

Our findings confirm that hypertension is common in Ouagadougou. Prevalence appears to remain stable in the last decade. There was no significant difference in prevalence between the informal and formal settings, once differences in age distribution were taken into account. Rural-to-urban migrants and unmarried women emerged as vulnerable populations for hypertension in these urban West African setting. Efforts should be made to reinforce healthy behaviors, particularly keeping a healthy body weight and regular physical activity, to control the emergence of cardiovascular diseases. In addition, the vulnerability of unmarried women should be recognized and targeted with gender equality policies.

\section{Competing interests}

The authors declare that they have no competing interests.

\section{Authors' contributions}

$\mathrm{BD}$ designed the study, analyzed the data, drafted and reviewed the paper. SK contributed to the study design, drafted and reviewed the paper. CR and AS managed data collection, drafted and reviewed the paper. MVZ designed the study, supervised data analysis, drafted and reviewed the paper. All authors read and approved the final manuscript.

\section{Acknowledgements}

We wish to thank Bill and Melinda Gates Foundation for awarding the first author a doctoral fellowship through the Programme Population et Santé en Afrique (PPSA). We extend our acknowledgments to Welcome Trust for its financial support in the data collection (Grant N WT081993MA). Many thanks to Ouagadougou Health and Demographic Surveillance System team for giving access to the data set.

\section{Author details}

'Département de Médecine Sociale et Préventive, École de santé publique, Université de Montréal, 850 Rue Saint Denis, 3ème étage, Bureau S03-806, Montréal, QC H2X 0A9, Canada. ${ }^{2}$ Institut de Recherche en Sciences de la Santé (IRSS), 03 BP 7192 Ouagadougou, Burkina Faso. ${ }^{3}$ Institut Supérieur des Sciences de la Population (ISSP), Université de Ouagadougou, 03 BP 7118 Ouagadougou, Burkina Faso. ${ }^{4}$ Institut d'Études Démographique et du parcours de vie (I-DEMO), Université de Genève, 40 Boulevard du pont d'Arve, 1211 Genève, Suisse. ${ }^{5}$ Institut de Recherche en Santé Publique de I'Université de Montréal (IRSPUM), Montréal, QC, Canada. ${ }^{6}$ Centre de 
Recherche du Centre Hospitalier de l'Université de Montréal (CRCHUM), Montréal, QC, Canada.

Received: 28 April 2014 Accepted: 26 August 2014 Published: 30 August 2014

\section{References}

1. Maher D, Smeeth L, Sekajugo J: Health transition in Africa: practical policy proposals for primary care. Bull World Health Organ 2010, 88(12):943-948.

2. Omran AR: The epidemiologic transition. A theory of the epidemiology of population change. Milbank Mem Fund Q 1971, 49(4):509-538.

3. Delisle H, Ntandou-Bouzitou G, Agueh V, Sodjinou R, Fayomi B: Urbanisation, nutrition transition and cardiometabolic risk: the Benin study. Br J Nutr 2012, 107(10):1534-1544.

4. Godfrey R, Julien M: Urbanisation and health. Clin Med 2005, 5(2):137-141.

5. World Health Organization: Global status report on noncommunicable diseases 2010. 2011. http://whqlibdoc.who.int/publications/2011/ 9789240686458_eng.pdf.

6. Murray CJ, Lopez AD: Mortality by cause for eight regions of the world: Global Burden of Disease Study. Lancet 1997, 349(9061):1269-1276.

7. Addo J, Smeeth L, Leon DA: Hypertension in sub-saharan Africa: a systematic review. Hypertension 2007, 50(6):1012-1018.

8. Damasceno A, Azevedo A, Silva-Matos C, Prista A, Diogo D, Lunet N: Hypertension prevalence, awareness, treatment, and control in mozambique: urban/rural gap during epidemiological transition. Hypertension 2009, 54(1):77-83.

9. Kearney PM, Whelton M, Reynolds K, Muntner P, Whelton PK, He J: Global burden of hypertension: analysis of worldwide data. Lancet 2005, 365(9455):217-223.

10. Agyemang C: Rural and urban differences in blood pressure and hypertension in Ghana, West Africa. Public Health 2006, 120(6):525-533.

11. Doulougou B, Kouanda S, Bado A, Nikiéma L, Zunzunegui MV: Hypertension in the adult population of Kaya Health and Demographic Surveillance System in Burkina Faso: Prevalence and associated factors. International Journal of Tropical Disease and Health 2014, 4(1):94-110.

12. United Nations: The Millennium Development Goals Reports 2012. New York: United Nations; 2012 http://www.un.org/millenniumgoals/pdf/MDG\% 20Report\%202012.pdf.

13. Niakara A, Nebie LV, Zagre NM, Ouedraogo NA, Megnigbeto AC: Connaissances d'une population urbaine sur l'hypertension arterielle: enquete prospective menee a Ouagadougou. Burkina Faso Bull Soc Pathol Exot 2003, 96(3):219-222

14. Niakara A, Fournet F, Gary J, Harang M, Nebie LV, Salem G: Hypertension, urbanization, social and spatial disparities: a cross-sectional populationbased survey in a West African urban environment (Ouagadougou, Burkina Faso). Trans R Soc Trop Med Hyg 2007, 101(11):1136-1142.

15. Rossier C, Soura A, Baya B, Compaore G, Dabire B, Dos Santos S, Duthe G, Gnoumou B, Kobiane JF, Kouanda S, Lankoande B, Legrand T, Mbacke C, Millogo R, Mondain N, Montgomery M, Nikiema A, Ouili I, Pison G, Randall S, Sangli G, Schoumaker B, Zourkaleini Y: Profile: the Ouagadougou Health and Demographic Surveillance System. Int J Epidemiol 2012, 41(3):658-666.

16. World Health Organization: The STEPS Instrument and Support Materials. Geneva: World Health Organization; 2006. http://www.who.int/chp/steps/ instrument/en/index.html\#.

17. Babor TF, Higgins-Biddle JC, Saunders JB, Monteiro MG: AUDIT: The Alcohol Use Disorders Identification Test. Geneva: World Health Organization; 2001. http://www.talkingalcohol.com/files/pdfs/WHO audit.pdf.

18. Agyemang C, Bruijnzeels MA, Owusu-Dabo E: Factors associated with hypertension awareness, treatment, and control in Ghana, West Africa. $J$ Hum Hypertens 2006, 20(1):67-71.

19. Jenson A, Omar AL, Omar MA, Rishad AS, Khoshnood K: Assessment of hypertension control in a district of Mombasa, Kenya. Global public health 2011, 6(3):293-306

20. Tesfaye F, Byass P, Wall S: Population based prevalence of high blood pressure among adults in Addis Ababa: uncovering a silent epidemic. BMC Cardiovasc Disord 2009, 9:39.

21. van de Vijver SJ, Oti SO, Agyemang C, Gomez GB, Kyobutungi C: Prevalence, awareness, treatment and control of hypertension among slum dwellers in Nairobi, Kenya. J Hypertens 2013, 31(5):1018-1024.

22. Agyemang C, Nicolaou M, Boateng L, Dijkshoorn H, van de Born BJ, Stronks K: Prevalence, awareness, treatment, and control of hypertension among
Ghanaian population in Amsterdam, The Netherlands: the GHAIA study. European journal of preventive cardiology 2013, 20(6):938-946.

23. Gibson J, Stillman S, McKenzie D, Rohorua H: Natural experiment evidence on the effect of migration on blood pressure and hypertension. Health Econ 2013, 22(6):655-672.

24. Unwin N, James P, McLarty D, Machybia H, Nkulila P, Tamin B, Nguluma M, McNally R: Rural to urban migration and changes in cardiovascular risk factors in Tanzania: a prospective cohort study. BMC Public Health 2010, 10:272.

25. Duboz P, Macia E, Chapuis-Lucciani N, Boetsch G, Gueye L: Migration and hypertension in Dakar, Senegal. Am J Phys Anthropol 2012, 149(2):250-258.

26. Zhang Z, Hayward M: Gender, the marital life course, and cardivascular diseases in late midlife. J Marriage Fam 2006, 68:639-657.

27. Briasoulis A, Agarwal V, Messerli FH: Alcohol consumption and the risk of hypertension in men and women: a systematic review and meta-analysis. J Clin Hypertens (Greenwich) 2012, 14(11):792-798.

28. Pires JE, Sebastiao YV, Langa AJ, Nery SV: Hypertension in Northern Angola: prevalence, associated factors, awareness, treatment and control. BMC Public Health 2013, 13(1):90.

29. Addo J, Amoah AGB, Koram KA: The changing patterns of hypertension in Ghana: A study of four rural communities in the Ga District. Ethn Dis 2006, 16:894-899.

30. Fezeu L, Kengne AP, Balkau B, Awah PK, Mbanya JC: Ten-year change in blood pressure levels and prevalence of hypertension in urban and rural Cameroon. J Epidemiol Community Health 2010, 64(4):360-365.

31. Zeba AN, Delisle HF, Renier G, Savadogo B, Baya B: The double burden of malnutrition and cardiometabolic risk widens the gender and socio-economic health gap: a study among adults in Burkina Faso (West Africa). Public Health Nutr 2012, 15(12):2210-2219.

32. Rose G: Sick individuals and sick populations. Int J Epidemiol 1985, 14(1):32-38.

33. De Ramirez SS, Enquobahrie DA, Nyadzi G, Mjungu D, Magombo F, Ramirez M, Sachs SE, Willett W: Prevalence and correlates of hypertension: a cross-sectional study among rural populations in sub-Saharan Africa. $J$ Hum Hypertens 2010, 24(12):786-795.

34. Bosu WK: Epidemic of hypertension in Ghana: a systematic review. BMC Public Health 2010, 10:418.

doi:10.1186/1471-2458-14-893

Cite this article as: Doulougou et al:: Differences in hypertension between informal and formal areas of Ouagadougou, a sub-Saharan African city. BMC Public Health 2014 14:893.

\section{Submit your next manuscript to BioMed Central and take full advantage of:}

- Convenient online submission

- Thorough peer review

- No space constraints or color figure charges

- Immediate publication on acceptance

- Inclusion in PubMed, CAS, Scopus and Google Scholar

- Research which is freely available for redistribution 